Editorial

\section{Relationship between Kingdoms}

Dr. Bhawisha Joshi, MD, Guest Editor ${ }^{1}$

1 India

Homœopathic Links 2015;28(2):69-70.

\section{H. A. Roberts writes in the first chapter of his book:}

In the first place, homeopathy offers to the independent mind an opportunity continually to seek new verifications of the natural laws upon which this system of medicine is based. It opens up vast fields to the pioneer, and we cannot gauge the distance that eager minds may travel, nor how greatly the interpretations of these laws may influence the civilization of the future.

(The Principles \& Art of Cure by Homeopathy, Chapter 1: What Has Homeopathy to Offer the Young Man?) ${ }^{1}$

It is neither surprising that Roberts expected the next generations to move ahead in homeopathy nor is it astonishing that we have.

Change is the only constant in this universe and one that supports the theory of evolution.

A science, a philosophy, a machine, living organisms, a planet, a star ... anything that does not 'move' or change or evolve will stagnate and eventually become extinct.

Hahnemann himself wrote six editions of the Organon in his lifetime, and with every edition he changed, corrected, improvised and even added new potencies and new theories (e.g., the theory of chronic diseases, the use of high potencies and finally the millesimal potency). Had he not been continuously developing and evolving, we would not have had the gift of miasms that is such a strong pillar of homeopathy today.

We as homeopaths need to keep evolving and to accept evolution in our science. In fact, whether we accept it or not, we have evolved and every generation from Hahnemann and Boenninghausen to Boger, Kent and recent masters such as Vithoulkas have taken this science one step further. With the current generation of leaders such as Jan Scholten, Rajan Sankaran, Jeremy Sherr, to name but a few, the science has almost taken a quantum leap and connected to, or bridged with, the realms of philosophy and metaphysics.

If I examine my own cases and provings from 1997 and compare them with my recent work in 2014, I can see much change and development.

This does not mean that I dismiss or discredit the work from 17 years ago, nor do I consider my old philosophies and

thoughts to be redundant, as I have taken it all in my stride and today I can stand much wiser as a result of those years of experience, learning as well as stumbling.

We need to be open to new ideas and to observe the various phenomena occurring in our practice. They are there to teach us something, and we are here to learn. Closed and insecure, we only deprive ourselves of the evolution of information and experience that is a nature's gift.

Yet I also believe that new ideas must be examined and tested before we accept them, rather than jumping at them irrationally with childish excitement.

The study of families, kingdoms and groups may appear to be a recent phenomenon, but it has its roots in the minds of stalwarts.

In the Prefatory Note to Vol. II of A Dictionary of Practical Materia Medica, John Henry Clarke Writes:

'Now that the MATERIA MEDICA is complete, my attention will be given to the compilation of a Clinical Repertory and Concordium. In the MATERIA MEDICA each remedy is provided with a Clinical Index under its "CLINICAL" heading: in the Repertory I propose to provide a general index to all these headings. In addition there will be an index to CAUSES (given under the CAUSATION heading) and to temperaments and constitutions. I propose to add a Concordium, or table, showing the relations in nature of the different remedies, e.g., the natural orders in the case of plants and animals' ${ }^{2}$

'Dr. Clarke has arranged a chapter in which is given the Natural Orders, with the list of the individual members of each natural order. This is something that we have been looking for. It enables one to investigate the strong therapeutic likeness which will often be found to exist between members of the same botanical group-a very interesting study indeed'.

(Hahnemannian Monthly.) ${ }^{3}$

Before I sign off, I would like to draw readers' attention to another favourite of mine-Provings. We may wonder whether new provings are necessary when we already have such a plethora of remedies. Here is what Kent writes on the matter in his book Lectures of Materia Medica in the chapter Naja:

(C) 2015 Thieme Medical and Scientific Publishers Private Ltd.
DOI http://dx.doi.org/ $10.1055 / \mathrm{s}-0035-1552927$. ISSN 1019-2050.
Address for correspondence Dr. Bhawisha Joshi, MD (Hom), Dr. Joshis Homoeopathic Care, B 101, Rushi Sanket, Mahant Road, Vile Parle, Mumbai 400057, India (e-mail: bhawisha@drjoshisclinic. com). 
'Another idea has been advanced that in any particular region, the vegetable kingdom provides all that is necessary for curing in that region. If we were acquainted with all the vegetable growths, how much we would know in comparison with what we do know! It is highly probable that there is a throwing off from the sick human race of something that is absorbed by the plants. The evils that are thrown off by man may be absorbed by the vegetable kingdom. Plants will correspond to men in the region in which they grow, if there is anything in this. In two thousand years there might be a necessity for some kind of a check upon the growth of plants. The absorption of these evils may cause them to vary in species, and if they continue to grow and each to absorb the evils from the human race, they will continue to differ. This favours evolution and explains it in a sense'. ${ }^{4}$

Kent is not just talking of proving new substances, but he introduces us to the need to reprove old remedies a few hundred years hence as these plants are also evolving, courtesy of the effects of human development.

I hope you enjoy reading the articles in this issue. Though Jan Scholten (whom I hold very hold high regards for) has contributed a brilliant article on his recent work on the phases of plants, along the lines of his work on minerals, some of my dear friends and colleagues and I have drawn parallels between the animal kingdom and the periodic table.

Several cases had been sent for this issue by many more friends and like-minded people, and I regret that some of these will have to be saved for the next issue due to want of space.

The articles on homoeoprophylaxis and the measles craze will surely address current burning issues.

Patricia Hatherly's beautiful provings of the Uluru (Ayer's Rock), Brachychiton rupestris (Queensland Bottle Tree) and Lac macropi gigantei (Kangaroo Milk) are a treat for the enthusiast's soul.

\section{References}

1 Roberts HA. The Principles \& Art of Cure by Homeopathy. Reprinted ed. New Delhi, India: B. Jain Publishers; 1993

2 Clarke JH. A Dictionary of Practical Materia Medica. New Delhi, India: B. Jain Publishers; 1986

3 Hahnemann M. Preface. In: Clarke JH, ed. A Dictionary of Practical Materia Medica. New Delhi, India: B. Jain Publishers; 1986

4 Kent JT. Lectures of Materia Medica. Chapter on Naja, 2nd ed. Indian edition IBPP. New Delhi, India: Indian Books \& Periodicals Publishers; 1911

\section{Call for Articles}

\section{Have your say on Homoeoprophylaxis}

The series of articles by $\mathrm{Dr}$ Isaac Golden and colleagues examining homoeoprophylaxis will conclude in 2016 with an edition of Homoeopathic Links devoted to the topic. Dr Golden will be guest editor. Leading homeopaths who both support and oppose HP have been invited to contribute.

If you have a deep interest in this topic or valuable experiences you wish to share you are now invited to have your say. Dr Golden will bring all contributions together in order to present an overview on the topic of homoeoprophylaxis. Contributions should be between 500-1,500 words, and include more than just declarations of support or opposition to the use of HP. Longer contributions may be considered to be published as a separate article if an appropriate proposal is submitted.

Please send your papers to Dr Golden at i.golden@federation.edu.au no later than 1/9/2015. Please include the following:your name, country, length of homeopathic practice and email address. Contributions must be in English. You may request that your name be withheld from publication. This unusual provision is offered due to the possibly confronting nature of disagreements about this topic.

In case you wish to offer an article for publication it should include a short summary, 3-6 keywords, a short bio including information relevant to the topic and a list with references of sources used. Please ask the editor for guidelines for authors at journal@homeolinks.nl 